\title{
Biodiversitas Mangrove di Desa Terapung dan Totobo Sulawesi Tenggara
}

\author{
Erfina $^{1^{*}}$ Sutriani Kaliu ${ }^{2}$ \\ Program Studi Pendidikan Biologi, Universitas Sembilanbelas November Kolaka \\ e-mail: ${ }^{1}$ finaerfina8@ gmail.com, ${ }^{2}$ sutriani.kaliu@ gmail.com
}

\begin{abstract}
Abstrak
Mangrove adalah ekosistem lahan basah pasang surut yang sangat produktif dan ditemukan di sepanjang pantai tropis maupun subtropic, mempunyai peranan sangat penting di daerah estuaria, merupakan ekosistem yang sangat unik dan rapuh serta sebagai daerah pertemuan antara lingkungan darat dan laut. Indonesia sebagai negara maritim dan kepulauan terbesar di dunia dengan jumlah pulau mencapai 17.504 pulau dan panjang garis pantai sekitar $95.181 \mathrm{~km}$ dengan kondisi biofisik lingkungan dan iklim beragam. Hal ini, didukung dengan ekosistem mangrove terluas di dunia (3.49 juta ha), dimana terdapat sekitar 202 jenis mangrove dengan 166 jenis di Pulau Jawa, 157 jenis di Pulau Sumatera, 150 jenis di Pulau Kalimantan, 142 jenis di Pulau Irian Jaya, 133 jenis di Pulau Maluku, 120 jenis di Kepulauan Sunda Kecil dan 135 jenis di Pulau Sulawesi, sehingga Indonesia dikenal sebagai negara mega biodiversitas. Penelitian ini bertujuan melihat biodiversitas mangrove dan sebagai acuan dalam menambah informasi (database) mengenai kelimpahan mangrove yang ada di Sulawesi Tenggara. Penelitian dilaksanakan di pesisir pantai Desa Terapung dan Desa Totobo Sulawesi Tenggara. Pengambilan data vegetasi mangrove di lokasi penelitian menggunakan metode tanpa plot Point Centered Quarter Method (PCQM) yang masing-masing lokasi diletakan dibuat baseline $100 \mathrm{~m}$, jarak antara sub transek $25 \mathrm{~m}$ dan pengukuran parameter lingkungan. Hasil penelitian di dua lokasi ditemukan 7 spesies yaitu: Bruguiera gymnorrhiza (L.) Lamk., Bruguiera sexangula (Lour). Poir. Rhizophora mucronata Lamk. Xylocarpus granatum Keon. Sonneratia Alba J.E Smith dan Avesinnia marina (Forsk) Vierh. Namun, jenis yang banyak ditemukan pada stasiun 1 (desa Marobo), karena didukung oleh subtract dan parameter lingkungan (pH tanah: 5 -7,8), (Kelembaban udara: 72,1-81,55\%), (Temperatur udara: 30,45-34,4 ${ }^{\circ} \mathrm{C}$ ), (intensitas cahaya $27.5--541.5 \mathrm{~cd}$ ) dan salinitas berkisar (20 -- 30\%).
\end{abstract}

Kata kunci: Biodiversita, Mangrove, Desa Terapung, Totobo

\section{PENDAHULUAN}

Mangrove adalah ekosistem lahan basah pasang surut yang sangat produktif dan ditemukan di sepanjang pantai tropis maupun subtropis (Osland et al., 2017), mempunyai peranan sangat penting di daerah estuaria (Jupriyati et al., 2013), merupakan ekosistem yang sangat unik dan rapuh serta sebagai daerah pertemuan antara lingkungan darat dan laut (Lewis et al., 2011). Indonesia sebagai negara maritim dan kepulauan terbesar di dunia dengan jumlah pulau mencapai 17.504 pulau dan panjang garis pantai sekitar $95.181 \mathrm{~km}$ dengan kondisi biofisik lingkungan dan iklim beragam (Kusmana, 2011). Hal ini menggambarkan bahwa Negara Kesatuan Republik Indonesia merupakan negara yang unik karena tersusun oleh belasan ribu pulau dan kepulauan, serta tersebar di seputar khatulistiwa dan terletak diantara dua benua (Asia dan Australia) maupun dua samudera (Pasifik dan Hindia) (KPPN, 2016), didukung dengan ekosistem mangrove terluas di dunia (3.49 juta ha), dimana terdapat sekitar 202 jenis mangrove dengan 166 jenis di Pulau Jawa, 157 jenis di Pulau Sumatera, 150 jenis di Pulau Kalimantan, 142 jenis di Pulau Irian Jaya, 133 jenis di Pulau Maluku, 120 jenis di Kepulauan Sunda Kecil dan 135 jenis di Pulau Sulawesi, (Noor et al., 2006), sehingga Indonesia dikenal sebagai negara mega biodiversity (Keong, 2015).

Sulawesi Tenggara saat ini kondisi hutan mangrove sedang mengalami tekanan yang berat serta mengalami kekurangan luasan di beberapa kawasan pesisir terutama di wilayah yang berbatasan dengan laut

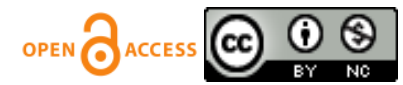


lepas, sehingga akan membuat warga yang ada di pesisir menderita bila terjadi air pasang yang tinggi (Zainuri et al., 2017). Menurut Polidoro et al., (2010) enam belas persen (16\%) spesies vegetasi mangrove dunia akan mengalami risiko kepunahan. Hal ini disebabkan karena tekanan terhadap kawasan mangrove yang tiada hentinya seperti berkembangnya pusat-pusat kegiatan dan berbagai aktivitas manusia, juga disebabkan oleh beberapa aspek kegiatan: a) pembangunan fasilitas rekreasi; b) pengembangan permukiman; dan c) pemanfaatan lahan pasang surut untuk kepentingan budidaya pertambakan. Seperti yang telah terjadi di daerah desa Terapung dan desa Totobo. Mengingat banyaknya sumberdaya hayati di Sulawesi Tenggara yang masih belum teridentifikasi dan pentingnya ekosistem mangrove bagi kehidupan sekitarnya, sehingga perlu dilakukan kajian Keanekaragaman Mangrove di Desa Terapung dan Totobo Sulawesi Tenggara secara berkala. Hal ini berguna sebagai upaya eksplorasi, pelestarian, pengelolaan dan dasar evaluasi ekosistem mangrove kedepannya, sehingga biodiversitas ekosistem mangrove di Sulawesi Tenggara tetap terjaga dan lestari.

\section{METODE PENELITIAN}

Penelitian dilaksanakan di desa Terapung dan Totobo provinsi Sulawesi Tenggara selama 2 bulan dilapangan pada bulan Mei-Juni tahun 2020. Kawasan desa Terapung terletak pada $05^{\circ} 12^{\prime}-05^{\circ} 8^{\prime}$ Lintang Selatan dan $122^{0} 18^{\prime}-122^{0}$ 20' Bujur Timur (Anonim, 2014) dan desa Totobo (S"04.16.260. E"121.60.892) Lintang Selatan dan (S"04.16.957. E”121.60.945) Bujur Timur Provinsi Sulawesi Tenggara. Lokasi penelitian stasiun 1 Desa Terapung berada di area pesisir pantai dari muara sungai sampai hilir, sementara stasiun 2 Desa Totobo berada di pesisir pantai dan depan jalan By Pass Kolaka dekat muara sungai. Topografi wilayah stasiun 1 dan 2 sangat landai kedalaman lumpur bervariasi stasiun $1(20-30 \mathrm{~cm})$ dan stasiun $2(15-25 \mathrm{~cm})$. Substrat pada stasiun 1 lumpur liat dan stasiun 2 lumpur berpasir. Lokasi penelitian dapat dilihat pada

Analisis keanekaragaman mangrove menggunakan Point Centered Quarter Method (PCQM) metode tanpa plot, dengan mengukur jarak terdekat dari titik sampling ke pohon terdekat dalam tiap kuadran. PCQM, sangat tepat digunakan dalam analisis vegetasi strata pohon. Parameter yang diamati adalah densitas, frekuensi, luas basal area, luas kanopi dan nilai penting. Pengambilan sampel stasiun 1 (Desa Terapung) lokasi penelitian di area pesisir pantai dari muara sungai sampai hilir, sementara stasiun 2 (Desa Totobo) berada di pesisir pantai dan depan jalan By Pass Pomalaa dekat muara sungai.

Ditarik garis transek sepanjang $100 \mathrm{~m}$, kemudian dibuat 5 sub transek berseling dengan jarak masingmasing $25 \mathrm{~m}$. Dalam 1 garis sub transek sepanjang $20 \mathrm{~m}$, kemudian dibuat 2 titik sampling dengan jarak masing-masing $10 \mathrm{~m}$ dengan sebaran masing-masing stasiun 1 dan 2 sebanyak 10 titik sampling. Data vegetasi dianalisis untuk melihat densitas, densitas relatif, frekuensi, frekuensi relatif, luas basal area, luas basal area relatif, luas kanopi, kanopi relatif dan nilai penting.

a) Menghitung rata-rata jarak (Densitas)

$\mathrm{D}=\frac{\text { total jarak semua individu sampel }}{\text { jumlah titik sampel } \times 4 \text { kuadran }}$

b) Densitas mutlak

$$
\mathrm{DM}=\frac{\text { unit luasan area }}{\text { rerata jarak }}
$$

c) Densitas relatif

$$
\text { DRspA }=\frac{\text { densitas spesies A }}{\text { total densitas seluruh spesies }} \times 100 \%
$$

d) Frekuansi

$$
\mathrm{F}=\frac{\text { jumlah titik sampling dengan sp A hadir }}{\text { jumlah total titik sampling }}
$$

e) Frekuensi relatif 


$$
\mathrm{FR}=\frac{\text { frekuensi spesies } \mathrm{A}}{\text { total frekuensi seluruh spesies }} \times 100 \%
$$

f) Luas basal area

$$
\text { Lba }=1 / 4 \times \pi \times \text { diameter }^{2}
$$

g) Luas basal area

$$
\mathrm{LbaR}=\frac{\text { luas basal area spesies A }}{\text { total lba seluruh spesises }} \times 100 \%
$$

h) Luas Kanopi

$$
\mathrm{K}=1 / 4 \times \pi \times(\mathrm{P} \times \mathrm{L})
$$

i) Kanopi relatif

$$
\mathrm{KR}=1 / 4 \times \pi(\mathrm{P} \times \mathrm{L}) \times 100 \%
$$

j) Nilai penting

$$
\mathrm{NP}=\mathrm{DR}+\mathrm{FR}+\mathrm{LBAR}+\mathrm{CANR}
$$

(Sancayaningsih dkk., 2014)

Data parameter fisikokimia meliputi pengukuran temperatur udara, kelembaban udara, $\mathrm{pH}$ tanah dan intensitas cahaya. Data diambil di setiap titik sampling, kemudian dimasukan kedalam tabel parameter fisikokimia. Data parameter fisiko kimia diambil 1 kali dalam 2 minggu dari bulan Mei-Juni 2020. Analisis parameter fisiko kimia secara deskriptif di dua stasiun.

\section{HASIL DAN PEMBAHASAN}

Hasil penelitian yang dilakukan di stasiun 1 dan 2 terdapat berbagai spesies mangrove yang tumbuh secara alami. Beberapa spesies yang diketahui melalui proses identifikasi dengan menggunakan bantuan internet, buku (Panduan Identifikasi Mangrove dan Panduan Lapangan Jenis-Jenis Tumbuhan Restorasi) (Noor et al., 2006), serta bertanya pada ahlinya. Berdasarkan hasil pengambilan data dan identifikasi jenis mangrove di lokasi penelitian, diperoleh 7 spesies mangrove dari dua lokasi yang berbeda. Jenis yang ditemukan secara taksonomi, termasuk nama lokal dapat dilihat pada tabel 1.

Tabel 1. Jumlah famili, jenis mangrove dan nama lokal di stasiun 1 dan 2

\begin{tabular}{clll}
\hline No. & Suku (Famili) & Jenis (Spesies) & Nama Lokal \\
\hline 1 & Rhizophoraceae & Bruguiera gymnoriza (L.) Lamk. & Tongke \\
2 & Rhizophoraceae & Bruguiera sexangula (Lour). Poir. & Tongke \\
3 & Rhizophoraceae & Rhizophora mucronata Lamk. & Bangko \\
4 & Meliaceae & Xylocarpus granatum Keon. & Kontafu \\
5 & Sonneratiacea & Sonneratia casiolaris (L) Engl & Muntu \\
6 & Sonneratiacea & Sonneratia Alba J.E Smith & Muntu \\
7 & Avesinniaceae & Avesinnia marina (Forsk) Vierh & Pejapi \\
\hline Jumlah & 4 Famili & 7 Spesies & \\
\hline
\end{tabular}


Tabel 2. Gambar deskripsi jenis mangrove stasiun 1 dan 2

\begin{tabular}{|c|c|c|c|c|c|}
\hline No & Gambar Mangrove & Nama Famili & $\begin{array}{l}\text { Nama } \\
\text { Spesies }\end{array}$ & $\begin{array}{l}\text { Nama } \\
\text { Lokal }\end{array}$ & Ciri Umum Spesies \\
\hline 1 & 58 & Rhizophoraceae & $\begin{array}{l}\text { Bruguiera } \\
\text { gymnoriza } \\
\text { (L) Lamk. }\end{array}$ & Tongke & $\begin{array}{l}\text { Bunga: merah muda } \\
\text { hingga merah. } \\
\text { Daun mahkota: } \\
\text { putih, coklat jika } \\
\text { tua dan masih } \\
\text { menempel pada } \\
\text { propagul ketika } \\
\text { jatuh. } \\
\text { Buah: hijau tua. } \\
\text { Akar: Lutut }\end{array}$ \\
\hline 2 & & Rhizophoraceae & $\begin{array}{l}\text { Bruguiera } \\
\text { sexangula } \\
\text { (Lour). Poir. }\end{array}$ & Tongke & $\begin{array}{l}\text { Bunga: kemerahan atau } \\
\text { kecoklatan. } \\
\text { Daun mahkota: putih, } \\
\text { coklat jika tua kadang } \\
\text { berambut halus ditepi. } \\
\text { Kelopak bunga: kuning } \\
\text { kehijauan atau } \\
\text { kemerahan. } \\
\text { Akar: Lutut }\end{array}$ \\
\hline 3 & & Rhizophoraceae & $\begin{array}{l}\text { Rhizophora } \\
\text { mucronata } \\
\text { Lamk. }\end{array}$ & Bangko & $\begin{array}{l}\text { Kelopak bunga: kuning } \\
\text { pucat dan berukuran } \\
\text { kecil. } \\
\text { Propagul bulat } \\
\text { memanjang, leher } \\
\text { kotilodon kuning } \\
\text { ketika matang. } \\
\text { Akar: Tunjang }\end{array}$ \\
\hline 4 & & Meliaceae & $\begin{array}{l}\text { Xylocarpus } \\
\text { granatum } \\
\text { Keon. }\end{array}$ & Kontafu & $\begin{array}{l}\text { Daun mahkota: putih } \\
\text { kehijauan. } \\
\text { Kelopak bunga: kuning } \\
\text { muda. } \\
\text { Buah: sangat besar } \\
\text { seperti bola. } \\
\text { Berkulit warna hijau } \\
\text { kecoklatan. } \\
\text { Akar: Papan }\end{array}$ \\
\hline
\end{tabular}




\begin{tabular}{|c|c|c|c|c|c|}
\hline 5 & 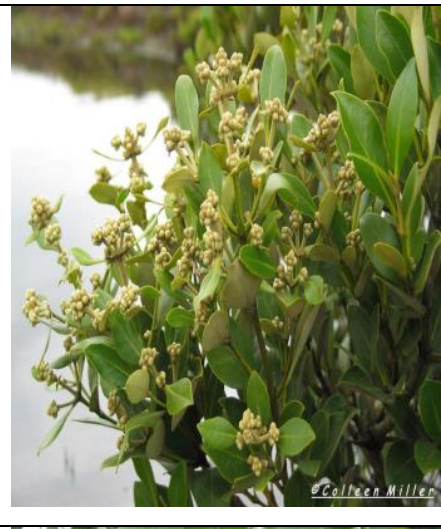 & Avicenniaceae & $\begin{array}{l}\text { Avecinnia } \\
\text { marina } \\
\text { (Forsk) } \\
\text { Vierh. }\end{array}$ & Pejapi & \begin{tabular}{|l|} 
Bunga bergerombol \\
seperti trisulamuncul \\
diujung tandan, bau \\
menyengat, nectar \\
banyak, berwarna \\
kuning pucat-jingga \\
tua. \\
Buah agak membulat \\
berwarna hijau agak ke \\
abua-abuan \\
Akar nafas tegak \\
dengan sejumlah \\
lentisel \\
\end{tabular} \\
\hline 6 & an. & Sonneratiaceae & $\begin{array}{l}\text { Sonneratia } \\
\text { Alba J.E } \\
\text { Smith }\end{array}$ & Muntu & \begin{tabular}{|l} 
Daun bulat telur \\
membalik, daun \\
mahkota putih mudah \\
rontok, benang sari \\
banyak ujungnya putih \\
dan pangkal kuning \\
Buah mengandung \\
banyak biji tidak akan \\
membuka pada saat \\
matang \\
Akar nafas \\
\end{tabular} \\
\hline 7 & & Sonneratiaceae & $\begin{array}{l}\text { Sonneratia } \\
\text { cassiolaris } \\
\text { (L.) Engl }\end{array}$ & Perepat & $\begin{array}{l}\text { Pucuk bunga bulat } \\
\text { telur, bunga } \\
\text { berbentuk } \\
\text { mangkok, kelopak } \\
\text { bunga berkulit } \\
\text { bagian luar hijau } \\
\text { didalam putih } \\
\text { kekuningan hingga } \\
\text { kehijauan, benang } \\
\text { sari putih dan } \\
\text { pangkal merah, } \\
\text { Akar nafas. } \\
\end{array}$ \\
\hline
\end{tabular}

\subsection{Hasl Analsis Data Vegetasi}

Berdasarkan perhitungan secara kuantitatif telah diperoleh deskripsi beberapa indikator keanekaragaman mangrove di pesisr pantai desa Terapung dan Totobo Sulawesi Tenggara. Hasil analisis variabel vegetasi mangrove meliputi densitas, densitas relatif, frekuensi, frekuensi relatif, luas basal area, luas basal area relatif, luas kanopi, kanopi relatif dan nilai penting dapat dilihat pada table:

Tabel 3. Nilai densitas jenis mangrove di stasiun 1 dan 2

\begin{tabular}{clccclccc}
\hline \multicolumn{2}{c}{ Stasiun 1 } & \multicolumn{1}{c}{ Stasiun 2 } \\
\hline No. & \multicolumn{1}{c}{ Nama spesies } & $\begin{array}{c}\text { Total } \\
\text { Ind }\end{array}$ & $\begin{array}{c}\text { D } \\
\text { ind/ha }\end{array}$ & $\begin{array}{c}\text { DR } \\
\%\end{array}$ & \multicolumn{1}{c}{ Nama Spesies } & $\begin{array}{c}\text { Total } \\
\text { Ind }\end{array}$ & $\begin{array}{c}\text { D } \\
\text { ind/ha }\end{array}$ & $\begin{array}{c}\text { DR } \\
\%\end{array}$ \\
\hline Pohon & & & & & & & & \\
1 & B. gymnoriza (L.) Lamk. & 37 & 1.52 & 81.8 & S. casiolaris (L) Engl. & 25 & 0.13 & 258.7 \\
2 & B. sexangula (Lour). Poir & 0 & 0.00 & 0.0 & S. Alba J.E Smith & 3 & 0.02 & 15.4 \\
3 & R. mucronata Lamk. & 16 & 0.28 & 15.3 & R. muconata Lamk. & 21 & 0.11 & 120.7 \\
4 & X. granatum Keon & 7 & 0.05 & 2.9 & A. marina (Forsk) Vierh. & 1 & 0.01 & 5.1 \\
\hline
\end{tabular}




\begin{tabular}{clccclccc}
\hline Sapling & & & & & & & \\
5 & B. gymnoriza (L.) Lamk. & 35 & 1.80 & 82.5 & S. casiolaris (L) Engl. & 33 & 3.09 & 139.5 \\
6 & B. sexangula (Lour). Poir & 0 & 0.00 & 0.0 & S. Alba J.E Smith & 2 & 0.01 & 9.1 \\
7 & R. mucronata Lamk. & 21 & 0.38 & 17.3 & R. muconata Lamk. & 29 & 3.27 & 120.6 \\
8 & X. granatum Keon & 4 & 0.00 & 0.2 & A. marina (Forsk) Vierh. & 32 & 4.26 & 130.8 \\
\hline Semai & & & & & & & & \\
9 & B. gymnoriza (L.) Lamk. & 41 & 5.00 & 87.2 & S. casiolaris (L) Engl. & 42 & 4.89 & 210.9 \\
10 & B. sexangula (Lour). Poir & 0 & 0.00 & 0.0 & S. Alba J.E Smith & 2 & 0.01 & 9.8 \\
11 & R. mucronata Lamk. & 19 & 0.73 & 12.8 & R. muconata Lamk. & 23 & 1.48 & 113.9 \\
12 & X. granatum Keon & 0 & 0.00 & 0.0 & A. marina (Forsk) Vierh. & 13 & 1.63 & 65.4 \\
\hline
\end{tabular}

Tabel 4. Nilai frekuensi jenis mangrove di stasiun 1 dan 2

\begin{tabular}{clcclcc}
\hline \multicolumn{2}{c}{ Stasiun 1 } & \multicolumn{7}{c}{ Stasiun 2 } \\
\hline No. & \multicolumn{1}{c}{ Nama spesies } & F & $\begin{array}{c}\text { FR } \\
\%\end{array}$ & \multicolumn{1}{c}{ Nama Spesies } & F & $\begin{array}{c}\text { FR } \\
\%\end{array}$ \\
\hline Pohon & & & & & \\
1 & B. gymnoriza (L.) Lamk. & 2.47 & 61.67 & S. casiolaris (L) Engl. & 5 & 258.7 \\
2 & B. sexangula (Lour). Poir & 0 & 0 & S. Alba J.E Smith & 0.6 & 15.4 \\
3 & R. mucronata Lamk. & 1.07 & 26.67 & R. muconata Lamk. & 4.2 & 120.7 \\
4 & X. granatum Keon & 0.47 & 11.67 & A. marina (Forsk) Vierh. & 0.2 & 5.1 \\
\hline Sapling & & & & & & \\
5 & B. gymnoriza (L.) Lamk. & 2.33 & 58.33 & S. casiolaris (L) Engl. & 6.6 & 139.5 \\
6 & B. sexangula (Lour). Poir & 0 & 0 & S. Alba J.E Smith & 0.4 & 9.1 \\
7 & R. mucronata Lamk. & 1.4 & 35 & R. muconata Lamk. & 5.8 & 120.6 \\
8 & X. granatum Keon & 0.27 & 6.67 & A. marina (Forsk) Vierh. & 6.4 & 130.8 \\
\hline Semai & & & & & & \\
9 & B. gymnoriza (L.) Lamk. & 2.73 & 68.33 & S. casiolaris (L) Engl. & 8.4 & 210.9 \\
10 & B. sexangula (Lour). Poir & 0 & 0 & S. Alba J.E Smith & 0.4 & 9.8 \\
11 & R. mucronata Lamk. & 1.27 & 31.67 & R. muconata Lamk. & 4.6 & 113.9 \\
12 & X. granatum Keon & 0 & 0 & A. marina (Forsk) Vierh. & 2.6 & 65.4 \\
\hline
\end{tabular}

Tabel 5. Nilai luas basa area jenis mangrove di stasiun 1 dan 2

\begin{tabular}{clcclcc}
\hline \multicolumn{1}{c}{ Stasiun 1 } & \multicolumn{7}{c}{ Stasiun 2 } \\
\hline No. & \multicolumn{1}{c}{ Nama spesies } & LBA & $\begin{array}{c}\text { LBAR } \\
\%\end{array}$ & \multicolumn{1}{c}{ Nama Spesies } & LBA & $\begin{array}{c}\text { LBAR } \\
\%\end{array}$ \\
\hline Pohon & & & & & & \\
1 & B. gymnoriza (L.) Lamk. & 1.82 & 96.50 & S. casiolaris (L) Engl. & 0.01 & 268.89 \\
2 & B. sexangula (Lour). Poir & 0 & 0 & S. Alba J.E Smith & 0.00 & 2.83 \\
3 & R. mucronata Lamk. & 0.06 & 3.37 & R. muconata Lamk. & 0.01 & 127.96 \\
4 & X. granatum Keon & 0 & 0.12 & A. marina (Forsk) Vierh. & 0.00 & 0.31 \\
\hline Sapling & & & & & & \\
5 & B. gymnoriza (L.) Lamk. & 2.54 & 95.8 & S. casiolaris (L) Engl. & 7.08 & 153.66 \\
6 & B. sexangula (Lour). Poir & 0 & 0 & S. Alba J.E Smith & 0.00 & 1.29 \\
7 & R. mucronata Lamk. & 0.11 & 4.22 & R. muconata Lamk. & 8.05 & 110.22
\end{tabular}




\begin{tabular}{clcclcc}
8 & X. granatum Keon & 0 & 0.00 & A. marina (Forsk) Vierh. & 13.86 & 134.82 \\
\hline Semai & & & & & & \\
9 & B. gymnoriza (L.) Lamk. & 19.66 & 97.89 & S. casiolaris (L) Engl. & 18.11 & 273.60 \\
10 & B. sexangula (Lour). Poir & 0 & 0 & S. Alba J.E Smith & 0.00 & 1.31 \\
11 & R. mucronata Lamk. & 0.42 & 2.11 & R. muconata Lamk. & 1.55 & 98.30 \\
12 & X. granatum Keon & 0 & 0 & A. marina (Forsk) Vierh. & 2.01 & 26.79 \\
\hline
\end{tabular}

Tabel 6. Nilai kanopi jenis mangrove di stasiun 1 dan 2

\begin{tabular}{|c|c|c|c|c|c|c|}
\hline & Stasiun 1 & & & Stasiun 2 & & \\
\hline No. & Nama spesies & $\begin{array}{c}\text { CAN } \\
\text { m2 }\end{array}$ & $\begin{array}{c}\text { CANR } \\
\% \\
\end{array}$ & Nama Spesies & $\begin{array}{c}\text { CAN } \\
\text { m2 }\end{array}$ & $\begin{array}{c}\text { CANR } \\
\% \\
\end{array}$ \\
\hline \multicolumn{7}{|c|}{ Pohon } \\
\hline 1 & B. gymnoriza (L.) Lamk. & 14440.3 & 89.6 & S. casiolaris (L) Engl. & 12675.1 & 317.4 \\
\hline 2 & B. sexangula (Lour). Poir & 0 & 0 & S. Alba J.E Smith & 55 & 0.63 \\
\hline 3 & R. mucronata Lamk. & 1552.2 & 9.6 & R. muconata Lamk. & 7131.1 & 81.8 \\
\hline 4 & X. granatum Keon & 132.6 & 0.8 & A. marina (Forsk) Vierh. & 15.7 & 0.18 \\
\hline \multicolumn{7}{|c|}{ Sapling } \\
\hline 5 & B. gymnoriza (L.) Lamk. & 1274.9 & 69.4 & S. casiolaris (L) Engl. & 629.4 & 60.7 \\
\hline 6 & B. sexangula (Lour). Poir & 0 & 0 & S. Alba J.E Smith & 6.3 & 0.54 \\
\hline 7 & R. mucronata Lamk. & 529.0 & 28.8 & R. muconata Lamk. & 3089.4 & 274.8 \\
\hline 8 & $\mathrm{X}$. granatum Keon & 32.5 & 1.8 & A. marina (Forsk) Vierh. & 671 & 63.9 \\
\hline \multicolumn{7}{|c|}{ Semai } \\
\hline 9 & B. gymnoriza (L.) Lamk. & 0 & 0 & S. casiolaris (L) Engl. & 0 & 0 \\
\hline 10 & B. sexangula (Lour). Poir & 0 & 0 & S. Alba J.E Smith & 0 & 0 \\
\hline 11 & R. mucronata Lamk. & 0 & 0 & R. muconata Lamk. & 0 & 0 \\
\hline 12 & X. granatum Keon & 0 & 0 & A. marina (Forsk) Vierh. & 0 & 0 \\
\hline
\end{tabular}

Tabel 7. Nilai penting jenis mangrove di stasiun 1 dan 2

\begin{tabular}{clclc}
\hline \multicolumn{1}{c}{ Stasiun 1 } & NP & \multicolumn{1}{c}{ Nama Spesies } & NP \\
\hline No. & \multicolumn{1}{c}{ Nama spesies } & & & \\
\hline Pohon & & 329.5 & S. casiolaris (L) Engl. & 1103.7 \\
1 & B. gymnoriza (L.) Lamk. & 0 & S. Alba J.E Smith & 34.2 \\
2 & B. sexangula (Lour). Poir & 55.0 & R. muconata Lamk. & 451.3 \\
3 & R. mucronata Lamk. & 15.5 & A. marina (Forsk) Vierh. & 10.8 \\
4 & X. granatum Keon & & & \\
\hline Sapling & & 306.0 & S. casiolaris (L) Engl. & 493.4 \\
5 & B. gymnoriza (L.) Lamk. & 0 & S. Alba J.E Smith & 20.0 \\
6 & B. sexangula (Lour). Poir & 85.4 & R. muconata Lamk. & 626.3 \\
7 & R. mucronata Lamk. & 8.66 & A. marina (Forsk) Vierh. & 460.3 \\
\hline & X. granatum Keon & & & \\
\hline Semai & & 253.4 & S. casiolaris (L) Engl. & 695.4 \\
9 & B. gymnoriza (L.) Lamk. & 0 & S. Alba J.E Smith & 20.8 \\
10 & B. sexangula (Lour). Poir & 46.6 & R. muconata Lamk. & 326.2 \\
11 & R. mucronata Lamk. & 0 & A. marina (Forsk) Vierh. & 157.6 \\
\hline 12 & X. granatum Keon & & &
\end{tabular}




\subsection{Parameter Lingkungan}

Parameter lingkungan yang mencakup temperatur udara, kelembaban udara, intensitas cahaya $\mathrm{pH}$ tanah dan salinitas. Dapat dilihat pada Tabe 8.

Tabel 8. Data Hasil Pengukuran Parameter Lingkungan di stasiun 1 (Desa Terapung) dan Stasiun 2 (Desa Totobo)

\begin{tabular}{lcccc}
\hline & Stasiun 1 & & Stasiun 2 & \\
\hline & Kanopi & Gap Kanopi & Kanopi & Gap Kanopi \\
\hline pH tanah & 7.8 & 7.6 & 5.1 & 5.2 \\
Kelembaban Udara $(\%)$ & 72.1 & 81.55 & 26.625 & 23 \\
Temperatur udara $\left({ }^{\circ} \mathrm{C}\right)$ & 34.4 & 34.4 & 30.45 & 32.7 \\
Intensitas Cahaya $(\mathrm{cd})$ & 29.7 & 541.5 & 27.5 & 529.5 \\
\hline
\end{tabular}

Nilai $\mathrm{pH}$ tanah di stasiun 1 dan 2 berkisar $(5-7,8)$ dengan nilai $\mathrm{pH}$ tanah tertinggi dimiliki oleh stasiun 1 kanopi dan gap kanopi, Kelembaban udara terendah dimiliki stasiun 2 kanopi dan gap kanopi berkisar (23-26\%), kisaran pH dan kelembaban udara masih bersifat netral. Bahri (2006) menyatakan bahwa pH dan kelembaban udara merupakan penentu unsur hara yang diserap oleh tanah serta mempengaruhi perkembangan mikroorganisme. Nilai $\mathrm{pH}$ dan kelembaban udara yang netral seperti yang ditemukan pada dua stasiun tersebut masih memungkinkan mudahnya tanah menyerap unsur hara. Wahyu dan widyastuti (1998) juga menambahkan bahwa $\mathrm{pH}$ tanah $(6,0-8,5)$ sangat berpotensi mendukung pertumbuhan penanaman mangrove

Temperatur udara di stasiun 1 dan 2 reratanya berkisar antara $\left(30,45-34,4^{0} \mathrm{C}\right)$ dan intensitas cahaya stasiun 1 dan 2 berkisar (27.5-541.5cd). Hal ini didukung dengan penelitian yang dilakukan oleh Zamroni dan Rohyani (2008) temperatur udara hutan mangrove Teluk Sepi $\left(27,8-31,7^{\circ} \mathrm{C}\right)$ masih merupakan suhu udara yang optimum bagi famili mangrove dan nilai persentase intensitas cahaya di stasiun 1 dan 2 tinggi pada gap kanopi disebabkan oleh pengukuran dilakukan pada siang hari pukul 13.00 WITA sampai selesai, sedangkan intensitas cahaya pada kanopi rendah disebabkan oleh rimbunya kanopi mangrove. Oleh karena itu, walaupun lingkungan tempat tumbuh mangrove yang memiliki radiasi sinar matahari tinggi dan suhu udara yang umumnya tinggi yang mendorong laju transpirasi tinggi pula namun, pada kenyataanya mangrove memiliki laju transpirasi rendah yang disebabkan oleh adaptasi anatomi daunnya (Onrizal, 2005)

Nilai salinitas pada stasiun 1 (Desa Maobo) dan stasiun 2 (Desa Totobo) berkisar (20-30\%o). Kusmana (2002) menyatakan bahwa salinitas bervariasi dari hari kehari dan dari musim kemusim. Pada siang hari di musim kemarau salinitas lebih tinggi dibandingkan waktu pagi dan malam hari musim penghujan dan waktu surut. Kisaran salinitas antara 20-30\% masih mendukung pertumbuhan mangrove lokasi pengamatan. Hal ini disebabkan secara umum habitat mangrove dapat ditemui pada daerah salinitas payau $2-22 \%$ sampai pada perairan bersalinitas $38 \%$.

\section{KESIMPULAN}

Berdasarkan hasil penelitian, mangrove yang ditemukan di dua lokasi terdapat 7 jenis, yaitu: Bruguiera gymnoriza (L.) Lamk., Bruguiera sexangula (Lour). Poir. Rhizophora mucronata Lamk. Xylocarpus granatum Keon. Sonneratia Alba J.E Smith dan Avesinnia marina (Forsk) Vierh. Namun, jenis yang banyak ditemukan pada stasiun 1 (desa Marobo), karena didukung oleh subtract dan parameter lingkungan ( $\mathrm{pH}$ tanah: 5-7,8), (Kelebaban udara: 72,1-81,55\%), (Temperatur udara: 30,45-34,4 ${ }^{0} \mathrm{C}$ ), (intensitas cahaya 27.5-541.5cd) dan salinitas berkisar (20-30\%o).

\section{DAFTAR PUSTAKA}

Bahri, A. F. 2006. Analisis Kandungan Nitrat dan Fosfat pada Sedimen Mangrove yang Termanfaatkan di Kecamatan Mallusetasi Kabupaten Barru. http://www.mangroveforest.com. Publikasi. 
Jupriyati R, Soenardjo N, Suryono CA. 2013. Akumulasi logam berat Timbal (Pb) dan pengaruhnya terhadap histologi akar mangrove Avicennia marina (Forssk). Vierh. di perairan Mangunharjo Semarang. Marine Research. 3(1):61-68

Kusmana, C. 2002. Pengelolaan Ekosistem Mangrove Secara Berkelanjutan dan berbasis Masyarakat. Makalah Disampaikan pada Lokakarya nasional Ekosistem Mangrove. Jakarta.

Kusmana C. 2011. Management Of Mangrove Ecosystem In Indonesia. Fakultas Kehutanan IPB. Bogor.JPSL (1) $2: 152$-157.

Keong CY. 2015. Sustainable resource management and ecological conservation of megabiodiversity: The Southeast Asian big-3 reality. International Journal of Environmental Science and Development. 6(11):876-882

Lewis M, Pryor R, Wilking L. 2011. Fate and effects of anthropogenic chemicals in mangrove ecosystems: A review. Environmental Pollution. 159:2328-2346

Noor YR, Khazali M, Suryadiputra INN. 2006. Panduan Pengenalan Mangrove di Indonesia. Bogor (ID):PHKA/WI-IP.

Onrizal. 2005. Adaptasi Tumbuhan Mangrove Pada Lingkungan Salin dan Jenuh Air. e-USU Repository. Universitas Sumatera Utara.

Osland M, Feher LC, Griffith KT, Cavanaugh KC, Enwright NM, Day RH, Stagg CL, Krauss KW, Howard RJ, Grace JB, Rogers K. 2017. Climatic controls on the global distribution, abundance, and species richness of mangrove forests. Ecological Monographs. 87(2):341-359

Polidoro BA, Carpenter KE, Collins L, Duke NC, Ellison AM, Ellison JC, Farnsworth EJ, Fernando ES, Kathiresan K, Koedam NE, Livingstone SR, Miyagi T, Moore GE, Nam VN, Ong JE, Primavera JH, Salmo SG, Sanciangco JC, Sukardjo S, Wang Y, Yong JWH. 2010. The loss of species: Mangrove extinction risk and geographic areas of global concern. Plos One. 5(4):1-10.

Sancayaningsih, R. P., Djohan, C. S. dan Hadisusanto, S. 2014. Petunjuk Praktikum Ekologi. Laboratorium Ekologi dan Konservasi. Fakultas Biologi Universitas Gadjah Mada. Yogyakarta.

Wahyu, S. L., dan Widyastuti, M. 1998. Identifikasi dan Pengukuran Parameter-Parameter Fisika Lapangan. Kerjasama Fakultas Geografi-UGM dan Bakosurtanal-BANGDA. Proyek MREP. Sulawesi Selatan.

Zainuri AM, Takwanto A, Syarifuddin A. 2017. Konservasi ekologi hutan mangrove di Kecamatan Mayangan Kota Probolinggo. Dedikasi. 14:1-7

Zamroni, Y., dan Rohyani, I. M. 2008. Litterfall productionof mangrove forest in the beach waters of Sepi bay, west Lombo. Biodiversitas. 9(4): 284 -- 287. 